\title{
LAW AND THE JEE: LESSONS FOR IHR IMPLEMENTATION
}

\author{
Akshara Narayan Menon, Emily Rosenfeld, and C. Adam Brush
}

In an increasingly globalized world, countries face infectious disease threats and public health emergencies that transcend borders, making health security of paramount importance. Legal frameworks, at both the international and national levels, can empower governments to strengthen public health and preparedness systems to better detect and respond to infectious disease threats and public health emergencies. The development of the International Health Regulations (IHR) (2005) and the Global Health Security Agenda (GHSA), and the resulting Joint External Evaluation (JEE), are examples of coordinated global efforts to build capacity to prevent, detect, and respond to the international spread of disease. This article uses 3 case studies to describe a role for law in IHR implementation. It highlights the Centers for Disease Control and Prevention's (CDC's) Global Health Security Public Health Law Project and describes how legal mapping data and the resources developed are being used by countries to strengthen health systems and support IHR implementation.

Keywords: International Health Regulations, Joint External Evaluation, Global public health law

$\mathrm{L}$ AWS ARE FOUNDATIONAL to US public health practice;* they establish and delineate the missions of public health agencies, provide authority and scope of public health functions, and appropriate necessary funds. ${ }^{1,2}$ The contribution of law to each of the 20th century's 10 great public health achievements in the United States highlights how law can be effectively used to improve public health outcomes. ${ }^{2}$ Former CDC Director Dr. William Foege has stated that law, along with epidemiology, is an essential tool in public health practice. ${ }^{3}$ Increasingly, law is being recognized and used as a tool for improving health on the global

*Public health law can be defined as the study of the legal powers and duties of the state, in collaboration with its partners, to assure the conditions for people to be healthy, and the limitations on the power of the state to constrain the autonomy, privacy, liberty, and proprietary or other legally protected interests of individuals for the common good. ${ }^{1}$ stage. ${ }^{4}$ Public health law can establish government authorities to coordinate responses to public health threats, to create and promote healthier environments, to generate the information base needed for timely action and policies, and many other public health activities. ${ }^{4}$ Thus, as countries strive to achieve global health security, international and national legal frameworks can play a critical role in assisting governments with improving their health infrastructures and operations.

\section{BACKGROUND}

\section{Global Efforts to Achieve Health Security: IHR (2005), GHSA, and JEE}

The International Health Regulations (IHR) (2005) are a legally binding agreement among 196 countries, including

Akshara Narayan Menon, JD, MPH, is a Public Health Analyst and Cherokee Nation Assurance Contractor, Public Health Law Program; Emily Rosenfeld, JD, MPH, and C. Adam Brush, MPH, MSW, are Public Health Analysts, Center for Global Health; all at the Centers for Disease Control and Prevention, Atlanta, Georgia. This document should not be construed as providing legal advice or counsel. Please seek the advice of an attorney or other qualified professional with questions regarding the application of law to a specific circumstance. The findings and conclusions in this article are those of the authors and do not necessarily represent the official views of the Centers for Disease Control and Prevention. 
all World Health Organization (WHO) Member States, to work together for global health security. 5 Through the IHR, countries have agreed to better prevent, detect, and respond to public health emergencies and the international spread of disease. ${ }^{5}$ In 2014, the United States launched the Global Health Security Agenda (GHSA) "to promote global health security as an international priority, and to spur progress toward full implementation of the IHR (2005)." "To measure this progress in building capacity for global health security, the United States developed an external country assessment tool. Recognizing the value of these external assessments, the WHO endorsed the use of this assessment approach. ${ }^{5, \dagger}$ Further, in 2016, the WHO worked with the United States and Finland to combine GHSA and IHR frameworks and develop one tool, the Joint External Evaluation (JEE), to measure progress toward IHR (2005) implementation. ${ }^{4}$

\section{The Role of Law in the JEE}

The JEE emphasizes the impact that law can have on IHR implementation by stating that even where nations' legal systems do not require new or revised legislation to implement health system changes, the revision of national laws may still be a "more efficient, effective or beneficial manner" to facilitate implementation. ${ }^{7}$ In fact, adequacy of public health law is measured throughout the JEE. The National Legislation, Policy, and Financing capacity area underscores the role of law and policy in IHR implementation for improved global health security. This capacity section calls on nations to support and enable IHR implementation with a legal framework. ${ }^{6}$ The indicators in this capacity area (see Figure 1) evaluate existing laws and newly revised laws that may facilitate IHR implementation and compliance. To earn a score of 4 or 5 , a country must have laws that specifically reference IHR core capacity areas, coordinate legal and regulatory frameworks between sectors, and facilitate the core and expanded functions of the IHR.

While the National Legislation, Policy, and Financing capacity area calls on countries to consider where revisions to law can strengthen IHR implementation, both direct and indirect calls for law also appear in a number of the other capacity areas. For example, in the JEE Biosafety and Biosecurity capacity area, the technical questions guide evaluators to look specifically to national legislation on biosafety and biosecurity, and it then breaks down what is expected for pathogen control procedures, laboratory licensing and enforcement, personnel security, and more. ${ }^{7}$ In other capacity areas, laws can establish the functional mechanism or agency responsible for individual technical

\footnotetext{
${ }^{\dagger}$ A recommendation of the review committee on the Role of the IHR (2005) in the Ebola Outbreak and Response was that external assessment of IHR core capacities, along with self-assessment, should become the recognized method for monitoring and strengthening the implementation of the IHR.
}

areas and identify the scope of that authority. For example, in the IHR Coordination, Communication, and Advocacy capacity area, national legislation establishing a functional mechanism for the coordination and integration of relevant sectors in IHR implementation may indicate developed coordination capabilities and can provide evidence for a higher JEE score for this capacity area. Some scholars have proposed reforming the JEE to recognize the importance of law in all of the technical areas, citing the insufficiency of having only 2 explicit indicators for legislation in the current instrument. ${ }^{8}$

The scores provided through JEE, both in the National Legislation capacity area and integrated throughout the other capacity areas, inform national leaders on the areas where national law can be developed to increase compliance and further implement the IHR. As of May 4, 2018, 75 countries had completed a JEE, and an additional 28 countries were scheduled. ${ }^{9}$ As more nations complete the JEE, more will direct resources and expertise to the capacity areas that have not achieved targets for IHR as measured in the JEE. Through use of legal instruments, countries have the opportunity to establish country norms in pursuit of improving IHR core capacities. Further, law can be a particularly efficient tool, as it can address multiple IHR core capacity areas. Global health and legal scholars emphasize that countries must develop legal and regulatory mechanisms in order to meet all IHR (2005) obligations, by translating the international agreement into laws that are relevant and manageable for country health officials at all government levels. ${ }^{10}$

\section{Legal Epidemiology}

Within the domestic public health law field, legal epidemiology has emerged as a transdisciplinary practice, defined as the scientific study of law as a factor in the cause, distribution, and prevention of illness and injury in a population. ${ }^{11}$ Two activities of this practice include legal mapping and legal evaluation. Legal mapping documents what the law says, and legal evaluation helps with understanding the impact of law. ${ }^{12}$ Health agencies at all levels of government in the United States have used evidence from legal mapping and evaluation studies to promote public health programs and activities. ${ }^{12}$ In the global context, mapping a country's legal landscape can assist with gap analyses and identifying opportunities to align its laws and national action plans with IHR commitments. Additionally, data gathered through legal mapping, such as observed practices from other countries, can serve as practical examples of how law is being used to address priority public health issues.

\section{MeTHODS}

The CDC's Center for Global Health (CGH), in collaboration with the Public Health Law Program (PHLP), used 
Figure 1. National Legislation, Policy and Financing Capacity Area

\begin{tabular}{|c|c|c|}
\hline \multirow[t]{2}{*}{ Score } & \multicolumn{2}{|c|}{ Indicators: National Legislation, Policy, and Financing } \\
\hline & $\begin{array}{l}\text { P.1.1 Legislation, laws, regulations, administrative } \\
\text { requirements, policies, or other government instruments } \\
\text { in place are sufficient for implementation of IHR. }\end{array}$ & $\begin{array}{l}\text { P.1.2 The state can demonstrate it has adjusted } \\
\text { and aligned its domestic legislation, policies, } \\
\text { and administrative arrangements to enable } \\
\text { compliance with the IHR (2005). }\end{array}$ \\
\hline No Capacity: 1 & $\begin{array}{l}\text { Assessment of relevant legislation, regulation, } \\
\text { administrative requirements, and other government } \\
\text { instruments for IHR (2005) implementation have } \\
\text { not been carried out. }\end{array}$ & $\begin{array}{l}\text { Legislation, regulation, administrative } \\
\text { requirements, and other government } \\
\text { instruments are not in place for the } \\
\text { implementation of the IHR (2005). }\end{array}$ \\
\hline $\begin{array}{l}\text { Limited } \\
\text { Capacity: } 2\end{array}$ & $\begin{array}{l}\text { Assessment of relevant legislation, regulation, } \\
\text { administrative requirements, and other government } \\
\text { instruments for IHR (2005) implementation has } \\
\text { been carried out. }\end{array}$ & $\begin{array}{l}\text { Assessment of relevant legislation, regulation, } \\
\text { administrative requirements, and other } \\
\text { government instruments for IHR ( } 2005) \\
\text { implementation has been carried out and needs } \\
\text { have been identified. }\end{array}$ \\
\hline $\begin{array}{l}\text { Developed } \\
\text { Capacity: } 3\end{array}$ & $\begin{array}{l}\text { Recommendations following assessment of relevant } \\
\text { legislation, regulation, administrative requirements, and } \\
\text { other government instruments are implemented. }\end{array}$ & $\begin{array}{l}\text { The country can demonstrate the existence and } \\
\text { use of relevant laws and policies in the various } \\
\text { sectors involved in the implementation of IHR. }\end{array}$ \\
\hline $\begin{array}{l}\text { Demonstrated } \\
\text { Capacity: } 4\end{array}$ & $\begin{array}{l}\text { Policies to facilitate IHR National Focal Point (NFP) care } \\
\text { and expanded functions and to strengthen core capacities }\end{array}$ & $\begin{array}{l}\text { The country has legislation references and/or } \\
\text { administrative requirements for specific areas } \\
\text { (eg, current legislation specifically addresses } \\
\text { IHR NFP designation and operations). }\end{array}$ \\
\hline $\begin{array}{l}\text { Sustainable } \\
\text { Capacity: } 5\end{array}$ & $\begin{array}{l}\text { Policies to facilitate IHR NFP care and expanded } \\
\text { functions and to strengthen core capacities incorporated } \\
\text { in the national health sector plan }\end{array}$ & $\begin{array}{l}\text { The country ensures coordination of the legal } \\
\text { and regulatory frameworks between sectors. }\end{array}$ \\
\hline
\end{tabular}

Targets: States parties should have an adequate legal framework to support and enable the implementation of all of their obligations and rights to comply with and implement the IHR (2005). In some states parties, implementation of the IHR (2005) may require new or modified legislation. Even where new or revised legislation may not be specifically required under the state party's legal system, states may still choose to revise some legislation, regulations, or other instruments in order to facilitate their implementation and maintenance in a more efficient, effective, or beneficial manner. States parties should ensure provision of adequate funding for IHR implementation through national budget or other mechanism.

Desired Impact: Legislation, laws, regulations, administrative requirements, policies, or other government instruments and budget in place sufficient support IHR implementation.

legal mapping processes that have been developed domestically and applied them globally to catalogue laws related to global health security. Initial collection of laws and analyses was conducted by external contractors with guidance from policy and legal analysts at CDC. Data were compiled on the presence or absence of national laws related to global health security for 25 countries in which CDC has or is providing technical support following the 2014-2016 Ebola outbreak in West Africa. The analyses focused on national laws of countries; subnational laws, international laws, policies, national strategic plans, and other guidance documents were not within the scope of this project.

The first step involved development of a framework to define legal domains, or areas of the law, relating to global health security and IHR core capacity areas. The domains were developed by reviewing and analyzing public health

\footnotetext{
Analysts were from FHI 360, the University of North Carolina at Chapel Hill, the O'Neill Institute for National and Global Health Law at Georgetown University, and the Temple University Beasley School of Law.
}

and legal literature, consulting with experts both within and outside of CDC, and by analyzing internal CDC technical guidance documents. As a result, 52 legal domains and 500 characteristics of laws were identified. This set of domains and characteristics provides a framework to map the relationship among law, global health security, and IHR implementation.

To identify laws for the mapping project, laws were collected from 3 sources from August 2015 through June 2016: online, the US Library of Congress, and in-country sources. Initially, approximately 750 laws were collected and analyzed. Collected laws were reviewed and coded using the legal domain framework for analysis. Coding these laws for each country provided a snapshot of the legal landscape for each country. Such legal mapping results provided an initial baseline to help understand the relationship between law and global health security in these countries and also provided a useful guide for dialogue with representatives from countries interested in legal review or revision.

Summaries of the legal mapping analysis were developed for each country. When paired with additional country- 
focused engagement, the legal domains framework and legal mapping data developed through the project provide a useful foundation for policy improvements to strengthen health infrastructure in countries. Each of the following case studies highlights how project resources were used in facilitating dialogues about country-led legal policy change and further underscore a role for law in IHR-related capacity-building efforts.

\section{Case Study 1}

\section{Liberia: Updating Public Health Law Title 33}

During the early days of the Ebola outbreak in 2014, Liberian government officials found they were missing the clear legal authorities needed to respond to the surging epidemic, including who was in charge of the response, how decisions were to be made, what resources were available, and how different sectors and actors were to work together. The government took the extraordinary step of issuing an emergency declaration to authorize public health actions needed to address the escalating crisis. ${ }^{13}$

In spring 2016, soon after the outbreak was finally contained, the Liberian Ministry of Health prioritized efforts to update the country's public health law (Title 33) to strengthen its public health infrastructure and to be better prepared to respond to the next public health emergency. Liberian officials recognized the need for an in-depth review of Title 33, enacted in 1976, to ensure that the revised law would reflect existing public health practices. For example, Title 33 contains a mandatory disease reporting list. Over the past 42 years, the disease threats in the country have changed, but the law does not contain the necessary provisions for adding additional diseases to the reporting list.

Between 2016 and 2018, the ministry of health conducted several law review workshops to provide opportunities for key stakeholders to build consensus on priority areas and update the 1976 law. As part of the stakeholder engagement process, CDC provided training on the role of law in improving public health and how law can be used as a proactive measure to build capacity to prevent, detect, and respond. CDC also made available the legal domains framework described earlier as well as mapping data on Liberia's status quo to assist stakeholders and drafters in identifying gaps and in thinking through how they might approach revisions. Moreover, the project's legal mapping data for Liberia not only helped stakeholders with their gap analyses but also was used during the JEE process to help the country to demonstrate an assessment of existing national laws and progress made toward updating their public health law to support IHR implementation.

As of May 2018, stakeholders are finalizing the updated law for submission to Liberia's legislature. Newly pro- posed provisions not only address emergency management, but also focus on other areas such as zoonotic diseases, laboratory biosafety and biosecurity, and reporting and surveillance. The proposed revisions are intended to support further progress toward full IHR implementation, including establishing a national IHR focal point. Liberia is not alone among countries seeking to update their public health laws to reflect current public health practices and to strengthen their health system overall. The recent Ebola outbreak in West Africa appears to have been a catalyst for many countries across the world to take a closer look at their existing legal frameworks and recognize law as a strategic tool that can serve as a reference point to provide guidance that can transcend government regimes.

\section{Case Study 2}

\section{Cote D'Ivoire and Togo: Emergency Operations Centers}

As countries aim to better respond to public health emergencies, law can play a crucial role in activating and operationalizing national public health emergency operations centers (PHEOCs). In an effort to achieve IHR compliance, member states have agreed to strengthen country capacity to promptly respond to public health risks by improving emergency operations center capabilities, including their ability to effectively communicate and coordinate during a public health emergency. Law can ensure that there are clear protocols for emergency management activities with defined roles for personnel and different sectors of government, which are key components for a timely and effective response. Cote d'Ivoire and Togo highlight different approaches to using law to operationalize their national public health emergency operations centers. Drawing on JEE indicators, proposed laws in Togo and Cote d'Ivoire are intended to increase IHR compliance, addressing areas such as surveillance, reporting, and emergency management. CDC collaborated with country officials to support workshops for stakeholders from multiple sectors to draft legal authorities to operationalize their national public health emergency operations centers. During each workshop, the legal domains framework and observed practices from other countries provided by CDC served as a reference to assist with identification of clear public health emergency operations centers activation and deactivation parameters and for the designation of specific roles and responsibilities of core operations center staff.

In an effort to build emergency management systems in Cote d'Ivoire, the ministry of health dedicated a space, identified key staff positions, and developed draft standard operating procedures. However, without legal authority, this public health emergency operations center could not 
activate emergency management response activities in the event of a national disease outbreak. To address this challenge, the ministry of health and the National Public Health Institute (INHP) held a workshop in August 2017 to assist with the development of legal authorities to authorize the establishment of the public health emergency operations center.

The legal domains framework provided by CDC helped stakeholders review particular characteristics of law to address country-specific challenges preventing the use of the public health emergency operations center. For example, the draft decree developed during the workshop now authorizes and delineates the organization and operational structure of the emergency operations center. This included authorizing the center as the lead entity responsible for coordination, preparation, and prevention of all public health emergencies, regardless of their origin. In addition, it also clarified that in the event of a public health emergency, the coordinator of the public health emergency operations center has the authority to activate and deactivate the center after consultation with both the prime minister and the minister of health. As of April 2018, the proposed legal decree $^{\S}$ is undergoing final validation. The proposed regulation in Cote d'Ivoire would not only assist the country's efforts to legally authorize the public health emergency operations center, but also would reinforce emergency management protocols in the country.

Togo approached the development of their public health emergency operations center by creating legal authorization for operations as an initial step in the development of their functional emergency operations center. During the drafting deliberations held in April 2017, laws from West African countries collected by CDC provided examples from other countries in the region, illustrating to stakeholders how neighboring countries were using law for IHR implementation. For example, IHR calls on nations to have systems that are regularly tested to identify and report a potential public health emergency of international concern (PHEIC). Therefore, some countries have chosen to establish laws that specifically mandate international reporting of disease during public health emergencies. While the emergency management authorities in Togo do not specifically address international reporting, they vest responsibility in the public health emergency operations center for timely communication of key information to national decision-making bodies and partners in an effort to ensure rapid coordination and response.

\footnotetext{
${ }^{\S}$ The legal systems in Togo and Cote d'Ivoire are built on structures of civil law transposed from the French legal system. The hierarchy of laws are as follows: constitution, signed and ratified international treaties, acts of parliament, ordinances, and regulations. Regulations are issued by the executive power and can be either decrees (for the prime minister and president) or arrêtes (for executive branch members apart from the president or prime minister).
}

In September 2017, the Togolese Secretary General of the ministry of health signed Arrête No. $165^{14}$ establishing legal authority for the operation of the public health emergency operations center. The measure establishes the range of allowable activities, structures, activation parameters, and the coordination mechanism for a multisectoral response. For instance, in an effort to achieve greater IHR compliance, the Arrête now includes measures to create a multisectoral and multidisciplinary steering committee to ensure coordination and involvement of other sectors during a public health emergency.

Thus, by first obtaining legal authorization, Togo was able to establish baseline norms for the smooth functioning of their public health emergency operations center with opportunities to further develop additional procedures for efficient operations.

\section{Case Study 3}

\section{Cambodia: Strengthening Biosafety and Biosecurity Laboratory Practices}

Recent years have seen incidences of global biosafety and biosecurity lapses in laboratories. ${ }^{15}$ With the growth of laboratory capacity across the world, laws to ensure the safety of their operation are a global concern. Law can improve laboratory operations by ensuring biosafety and biosecurity standards are required and not optional measures. Such biosafety and biosecurity laws can ensure that safety measures are integrated into default lab practices applicable to all laboratories across a country. Strengthening laboratory capacities often also includes training the workforce, introducing new diagnostics, and developing laboratory protocols, which can all be encompassed in law. With the increased number of higher-tiered biosafety laboratories, some countries are developing laboratory biosafety and biosecurity systems across human, animal, and agricultural facilities by enacting laws that create government accountability for regulating laboratory biosafety and biosecurity.

The legal domains framework and legal mapping data from the GHS Public Health Law project are relevant tools for other countries beyond the project's initial study sample. CDC's collaborative effort in Cambodia, a GHSA Phase II country, underscores the important role that law can play for all countries that are trying to build public health capacity. For example, as Cambodia continues to increase laboratory capabilities, law can help establish necessary management structures. This includes developing a controlling authority to oversee the possession, storage, and use of highly dangerous pathogens and toxins and enacting national requirements mandating the collection of laboratory inventory records to ensure the safety of the laboratory personnel and the general public. Laboratory leaders from the Cambodian ministry of health 
worked with CDC technical experts to facilitate a workshop geared toward strengthening biosafety and biosecurity practices in Cambodia's national laboratory network. During the workshop, held in November 2017, stakeholders used the legal domains framework to outline a proclamation $^{* *}$ for management of highly dangerous pathogens and toxins, including identification of agents and toxins of concern as well as regulation of authorized laboratories that can produce, use, and store these agents and toxins.

Drawing on recommendations outlined in Cambodia's JEE, this proclamation is intended to help increase IHR compliance by strengthening laboratory biosafety and biosecurity training and procedures involving the management and control of hazardous pathogens and toxins. The use of law is an important first step in implementing a top-down approach to strengthening biosecurity practices in Cambodian public health laboratories. This proclamation, when passed, will be the first of its kind in the Cambodian ministry of health created to improve laboratory safety involving the handling, storage, and transfer of dangerous biological pathogens.

\section{ConCLusion}

As countries strive to build their public health capacity for improved prevention, detection, and response to infectious disease threats, the law can be used as a tool to address public health challenges and improve outcomes. As the case studies demonstrate, law can be used not just as a reactive measure, but proactively to strengthen health systems and IHR implementation. In the case of global health security, laws can enable government agencies to develop, oversee, and coordinate programs to address antimicrobial resistance and zoonotic diseases, regulate laboratory biosafety and biosecurity, encourage routine vaccinations, establish national laboratory systems and surveillance and reporting requirements for certain diseases or public health events, and authorize emergency operation centers with specific authorities, among other functions. Understanding the existing legal landscape is critical for countries to determine opportunities to use law as a tool to strengthen public health infrastructure and support IHR compliance. As countries continue to face new disease threats and public health emergencies, laws are a strategic tool that can serve as a reference point to provide guidance that transcends government regimes.

\footnotetext{
${ }^{* *} \mathrm{~A}$ proclamation is a ministerial or inter-ministerial decision signed by the relevant minister(s). This Prakas is a ministerial proclamation signed by the minister of health establishing practices in lab facilities.
}

\section{ACKNOWLEDGMENTS}

The authors acknowledge the collaboration and support provided by ministries of health and other key partners in Cambodia, Cote D'Ivoire, Liberia, and Togo. In particular, the authors thank Dr. Sau Sokunna, Deputy Director, Department of Hospital Services, Ministry of Health [Cambodia]; Professor Dagnan Njo Simplice, Director General of Health, and Professor Vroh Joseph Benie, Director of the National Institute of Public Hygiene [Cote D'Ivoire]; Tomik Vobah, General Counsel, Ministry of Health [Liberia]; and Dr. Tossa Kokou, Coordonnateur du Centre d'opération des urgences de santé publique and Mr. Joël Kossivi Abalo, Legal Counsel, Ministry of Health [Togo]. The authors also thank CDC subject matter experts and country officers for their technical input and support, particularly Dr. Borann Sar, Dr. Gerald J Pellegrini, Dr. Serigne M Ndiaye, Dr. Desmond E Williams, Yvette Diallo, and Wilton (Chuck) Menchion. The authors also acknowledge Pierron Tackes, JD, for her significant contributions.

\section{REFERENCES}

1. Gostin LO, Wiley LF. Public Health Law: Power, Duty, Restraint. 3d ed. Oakland: University of California Press; 2016.

2. Goodman RA, Moulton A, Matthews G, et al. Law and public health at CDC. MMWR Suppl 2006;55(2): 29-33.

3. Foege WH. Redefining public health. J Law Med Ethics 2004;32(4 Suppl):23-26.

4. Magnusson R, Gostin LO, Patterson D, Cabrera O, NygrenKrug H. Advancing the Right to Health: The Vital Role of Law. Geneva: World Health Organization; 2017. http:// www.who.int/healthsystems/topics/health-law/health_lawreport/en/. Accessed August 1, 2018.

5. World Health Organization. About IHR. WHO website. http://www.who.int/ihr/about/en/. Accessed April 10, 2018.

6. Centers for Disease Control and Prevention. Global Health Security Action Packages. CDC website. Updated January 21, 2016. http://www.cdc.gov/globalhealth/security/action packages/default.htm. Accessed April 10, 2018.

7. World Health Organization. Joint External Evaluation Tool: International Health Regulations (2005). Geneva: WHO; 2016. http://apps.who.int/iris/bitstream/10665/204368/1/ 9789241510172_eng.pdf?ua=1. Accessed April 10, 2018.

8. Forzley M. Global Health Security Agenda: Joint External Evaluation and legislation-a 1-year review. Health Secur 2017;15(3):312-319.

9. World Health Organization. JEE dashboard. WHO website. https://extranet.who.int/spp/jee-dashboard. Accessed April 10, 2018.

10. Katz R, Sorrell EM, Kornblet SA, Fischer JE. Global Health Security Agenda and the International Health Regulations: moving forward. Biosecur Bioterror 2014;12(5):231-238.

11. Burris S, Ashe M, Levin D, Penn M, Larkin M. A transdisciplinary approach to public health law: the emerging 
MENON ET AL

practice of legal epidemiology. Annu Rev Public Health 2016; 37:135-148.

12. Burris S, Hitchcock L, Ibrahim J, Penn M, Ramanathan T. Policy surveillance: a vital public health practice comes of age. J Health Polit Policy Law 2016;41(6):1151-1173.

13. Constitution of Liberia, Emergency Powers, Chapter IX, Article 86 (1984).

14. Arrête No. 165/2017/MSPS/CAP/SG du 27 Septembre 2017. Portant creation, organisation, fonctionnement du centre d'operation des urgencies de sante publique (COUSP).

15. Gandhi BM. Recent incidences of global biosafety and biosecurity lapses in laboratories need relook at implementation of national policies. CBW Magazine July-December 2014. http://www.idsa.in/cbwmagazine/RecentIncidencesofGlobal Biosafety_bmgandhi. Accessed April 10, 2018.

Address correspondence to: Akshara Menon, JD, MPH CDC Public Health Law Program 4770 Buford Hwy., NE MS E-70 Atlanta, GA 30341

Email: amenon@cdc.gov 